\title{
The Wild West of ICOs
}

\author{
Shaen Corbet $^{a, b *}$, Douglas J. Cumming ${ }^{c}$ \\ ${ }^{a}$ DCU Business School, Dublin City University, Dublin 9, Ireland \\ ${ }^{b}$ School of Accounting, Finance and Economics, University of Waikato, New Zealand \\ ${ }^{c}$ FAU College of Business, Florida Atlantic University, Boca Raton, FL 33431, United States \\ ${ }^{d}$ Birmingham Business School, University of Birmingham, B15 2TT, UK \\ *Corresponding Author: shaen.corbet@dcu.ie
}

\begin{abstract}
This chapter sets out to establish the key issues that have become central within the market for Initial Coin Offerings (ICOs). Within this context, we provide a brief overview of the existing literature based on ICOs around the world, while explaining the motivations and styles of criminality that have occurred, the methods that have been widely used by cryptocurrency thieves, the potential for the innovation of theft within the sector and the related problems that such technological progress can potentially generate, and the types of market agents that have set out to potentially misuse ICOs for a variety of reasons at both the sovereign and corporate level. As cryptocurrency markets continue to evolve, it is imperative that policy-makers and regulators continue to monitor the potential development of sophisticated manipulation and cybercriminality techniques that have developed throughout the market for cryptocurrencies.
\end{abstract}

Keywords: Cryptocurrency; Initial coin offerings; Regulation; Illegality; Cybercriminality.

\section{Introduction}

As with any juvenile and rapidly expanding financial product, we must be aware of the potential for illicit and ethically-challenging decision-making while the boundaries for regulation continue to be designed. The very creation of cryptocurrencies has somewhat challenged regulators. Cryptocurrencies have provided an exceptionally easy platform that can be used for cross-border trade, but they can easily generate illicit activity. Companies and governments alike can utilise these products for somewhat 'questionable' practices. Three specific key concerns have been identified in recent literature: 1) the use of cryptocurrencies by governments to circumvent internationally-binding sanctions and controls; 2) the announcement of companies of their broad intentions to enter the cryptocurrency market, with little or no intention of following through on their commitments; and 3) the simplistic nature through which investor theft has continued to escalate within the scope 
of unregulated ICOs. These situations necessitate broad consideration by regulators and policymakers before the markets for cryptocurrencies can be truly identified to have evolved to levels similar to that of other types of traditional markets.

There have been a number of ethically-challenged issues that have arisen since the establishment of Bitcoin and other growing cryptocurrencies and digital asset types. Regulatory bodies and policy-makers alike have observed the growth of cryptocurrencies with a certain amount of scepticism based on the growing potential for illegality and malpractice through the use of cryptocurrencies. Some regulatory authorities, including the International Monetary Fund, have expressed their satisfaction with the product's development and the benefits that are contained within its continued growth, however, the Securities and Exchange Commission (SEC) amongst other international authorities have explicitly warned of the potential market manipulation techniques and ability to utilise fraudulent methods to defraud and steal from unwilling and unsuspecting investors.

The rest of this chapter is as follows. Section 2 presents a thorough review of the literature relating to the development and issues relating to ICOs and criminality in cryptocurrencies. Section 3 presents a review of the irregularities that have occurred in ICO markets, with emphasis on criminality, the use of ICOs by sovereign states and corporates and other examples of questionable ICOs. Section 4 presents and overview as to how the regulation has changed over time, while Section 5 concludes.

\section{Previous Literature}

Research based on ICOs has developed substantially since 2018, focusing on a broad number of areas such as underlying technology, financing and governance. It is notable that a developing strand of research has began to focus on issues such as illicit usage of ICOs and the developing role that cybercriminality has begun to play at the point at which cryptocurrencies begin their existence. Adhami et al. [2018] analysed the determinants of the success 253 ICOs to find that the probability success is higher if the code source is made available, when a token presale is organized, and when tokens allow contributors to access a specific service (or to share profits). While Hashemi Joo et al. [2019] identify that ICOs have generated billions of dollars of funding to startups and projects worldwide in less than two years, many successful ICOs yielded extremely high returns to investors. While the ICO is a revolutionary vehicle for business funding, it has raised concerns among users as well as potential investors about its risk and lack of regulation. The future of this innovative funding method highly depends on further development and placement of appropriate regulatory supervision, better understanding of risk and benefits and attaining the

confidence of users. Deng et al. [2018] focused on the September 2017 decision to ban ICOs in Chine, noting that the decision could hamper revolutionary technological developments and dampen the growth of this potentially beneficial market. The authors provide a non-exhaustive classification 
of the legal status of ICOs, including the pre-sale of products or services, offering of shares, issue of debentures, issue of derivatives, collective investment schemes and crowdfunding, as well as a possible regulatory reform of the current ICO ban in China. It is concluded that ICOs could be best regarded as pre-sale of products or services, whereas, the other five types of ICOs are highly likely to be considered as financial securities and thus should be subject to securities laws. O'Dair and Owen [2019] went as far as to investigate as to how new music ventures might obtain alternative entrepreneurial finance through token sales or ICOs, presenting evidence as to the breadth that this new developing market can reach. Fisch [2019] assessed the determinants of the amount raised in 423 ICOs while drawing on signalling theory to show that technical white papers and high-quality source codes increase the amount raised, while patents are not associated with increased amounts of funding. The results indicate that some of the underlying mechanisms in ICOs resemble those found in prior research into entrepreneurial finance, while others are unique to the ICO context. Felix and von Eije [2019] found that the average level of under-pricing of ICOs of $123 \%$ in the US and $97 \%$ in the other countries. The results for the US ICOs are significantly higher than for US IPOs on average and also higher than US IPOs at the beginning of the dot.com bubble. The authors also study the determinants of ICO under-pricing. Further, companies that use a large issue size or a pre-ICO (a sale of cryptocurrencies before the ICO) leave less money on the table.

Cohney et al. [2019] found that many ICOs failed even to promise that they would protect investors against insider self-dealing and that a significant fraction of issuers retained centralised control through previously undisclosed code permitting modification of the entities' governing structures. Barone and Masciandaro [2019] analyse separate money laundering techniques including the use of cryptocurrency to shed light on their relative role as an effective device for the criminal organisations to clean their illegal revenues. This research is developed further in the work of Corbet et al. [2019] who develop on the specific methods of illegality that have become a central issue in the developing cryptocurrency markets. Among the most alarming issues in recent years include that which have substantially damaged market integrity and identified the presence of potential fraud and criminal behaviour within the broad market system (Gandal et al. [2018]; Griffins and Shams [2018]). Such issues have become ever more alarming due to the multiple identified interactions between both product (Corbet et al. [2018]; Katsiampa et al. [2019]; Corbet and Katsiampa [2018]; Corbet et al. [2020]; Celeste et al. [2019]; Akhtaruzzaman et al. [2019]) and derivative types (Corbet et al. [2018]). Further, Corbet et al. [2019] investigate the effectiveness of technical trading rules in cryptocurrency markets and provide significant support for the moving average strategies, with emphasis on the variable-length moving average rule performs the best with buy signals generating higher returns than sell signals.

Nguyen et al. [2019] found that the negative impact of an Initial Public Offering (IPO) on existing stock prices can also be observed in the cryptocurrency market, where altcoin introductions are found through the use of Autoregressive-Distributed-Lag (ARDL) estimations, to reduce Bitcoin 
returns by $0.7 \%$. This result is found to be particularly pertinent as the average and median daily returns of Bitcoin are $0.6 \%$ and $0.3 \%$, respectively. Lahajnar and Rozanec [2018] analysed a number of factors, which directly or indirectly influence the successful implementation of ICO projects, and the researchers extracted the most important among them (model parameters). Huang et al. [2019] found using 915 ICOs issued in 187 countries between January 2017 and March 2018 that ICOs take place more frequently in countries with developed financial systems, public equity markets, and advanced digital technologies. The availability of investment-based crowdfunding platforms is also positively associated with the emergence of ICOs, while debt and private equity markets do not provide similar effects. Further, countries with ICO-friendly regulations have more ICOs, whereas tax regimes are not clearly related to ICOs. Chen [2019] focus on signals released in multiple channels in different ICO stages to investigate the relations between signal processing and information asymmetry. The authors find differing results throughout the different stages analysed, first indicating that in the crowd sale stage, high credible and easy-interpretable signals have significant influences on token sales. In the listing stage, low credible and easy-interpretable signals have significant effects on token trading. High credible and hard-interpretable signals, which deliver project fundamental information, lose their functions in both stages, causing information asymmetry in ICOs. Further, investor comments on social media, which is a multiple-way communication channel, play the role of information surveillance for ventures' voluntary disclosures.

\section{Some brief examples of cryptocurrency and ICO irregularities}

The very creation of cryptocurrencies has somewhat challenged regulators. Nakamoto [2008], while attempting to change the face of finance and fiat currency as we know it, challenged the views of many based on the viability of the cryptocurrencies at large. However, in the decade since the creation of Bitcoin, there have been a number of opportunistic manoeuvres that we must consider. Cryptocurrencies have provided an exceptionally easy platform that can be used for cross-border trade and generally illicit activity. Further, while pricing dynamics continue to be challenged as possessing a substantial bubble Corbet et al. [2018], companies and governments alike can utilise these products for 'questionable' practices. Three key concerns have been identified: 1) the use of fake ICOs to steal unsuspecting investor funds; 2) the use of cryptocurrencies by governments to circumvent internationally-binding sanctions and controls; and 3) the announcement of companies of their broad intentions to enter the cryptocurrency market, however, with little or no intention of following through on their commitments. Both of these situations contain substantial asymmetric information and moral hazards that necessitate broad consideration by regulators and policy-makers. In this section, we discuss each issue in detail. 


\subsection{Questionable motives, Criminality and ICO disappearance}

A controversial area of Initial Coin Offerings (ICOs) concerns financial regulators and businesses highlighting the importance of full and fair disclosure of corporate intention to incorporate blockchain technology. While ICOs can help companies to reduce the costs of raising capital, the lack of transparency and very limited information available for investors in the white papers might affect the corporate performance in the long run. The absence of a unified regulatory framework creates multiple speculation opportunities for all market players. At corporate level, the decision to adopt cryptocurrency or blockchain technology can change the corporate identity of the firm, for example, from a more conventional identity to that of a Fintech company, and attract a new group of investors. However, those intentions to adopt blockchain often stays at the stage of writing a white paper, making corporate announcements, or even simply changing the name of corporation, and not going further to actually launching the stated cryptocurrency or building the proposed platform. Thus corporations may try to take advantage of the euphoric and speculative investment motives and ride a wave on the cryptocurrency bubble. The explosive behaviour of the cryptocurrency markets can be compared with Dot.com bubble and related corporate name changes (Cooper et al. [2001]).

One of the largest signals that there exist the presence of irrational exuberance in cryptocurrency markets is denoted within not only the number of Initial Coin Offerings (ICOs) in recent years (see Figure 1), but indeed the source of these coin offerings. A substantial number of corporate entities have made announcements with regards to their intentions to enter the cryptocurrency sphere, for a host of differing reasons. This has raised alarm due to the inherent dangers associated with asymmetric information and moral hazard. As with any new financial product, we must be aware of the potential for illicit and ethically-challenging decision-making as the boundaries of regulation are designed. The very creation of cryptocurrencies has somewhat challenged regulators. Cryptocurrencies have provided an exceptionally easy platform that can be used for cross-border trade and generally illicit activity. Companies and governments alike can utilise these products for 'questionable' practices. Two key concerns have been identified: 1) the use of cryptocurrencies by governments to circumvent internationally-binding sanctions and controls; and 2) the announcement of companies of their broad intentions to enter the cryptocurrency market, however, with little or no intention of following through on their commitments. Both of these situations necessitate broad consideration by regulators and policy-makers. Regulatory bodies and policy-makers alike have observed the growth of cryptocurrencies with a certain amount of scepticism, based on this growing potential for illegality and malpractice. Foley et al. [2019] estimate that around $\$ 76$ billion of illegal activity per year involve Bitcoin ( $46 \%$ of Bitcoin transactions). This is estimated to be in the same region of the U.S. and European markets for illegal drugs, and is identified as 'black e-commerce'.

However, at the core of the main issue with ICOs is simply that of direct theft, which has occurred on multiple occasions, including the most simplistic of financial crime, where the host 
Figure 1: Number and monetary value of initial coin offerings, 2014-2018

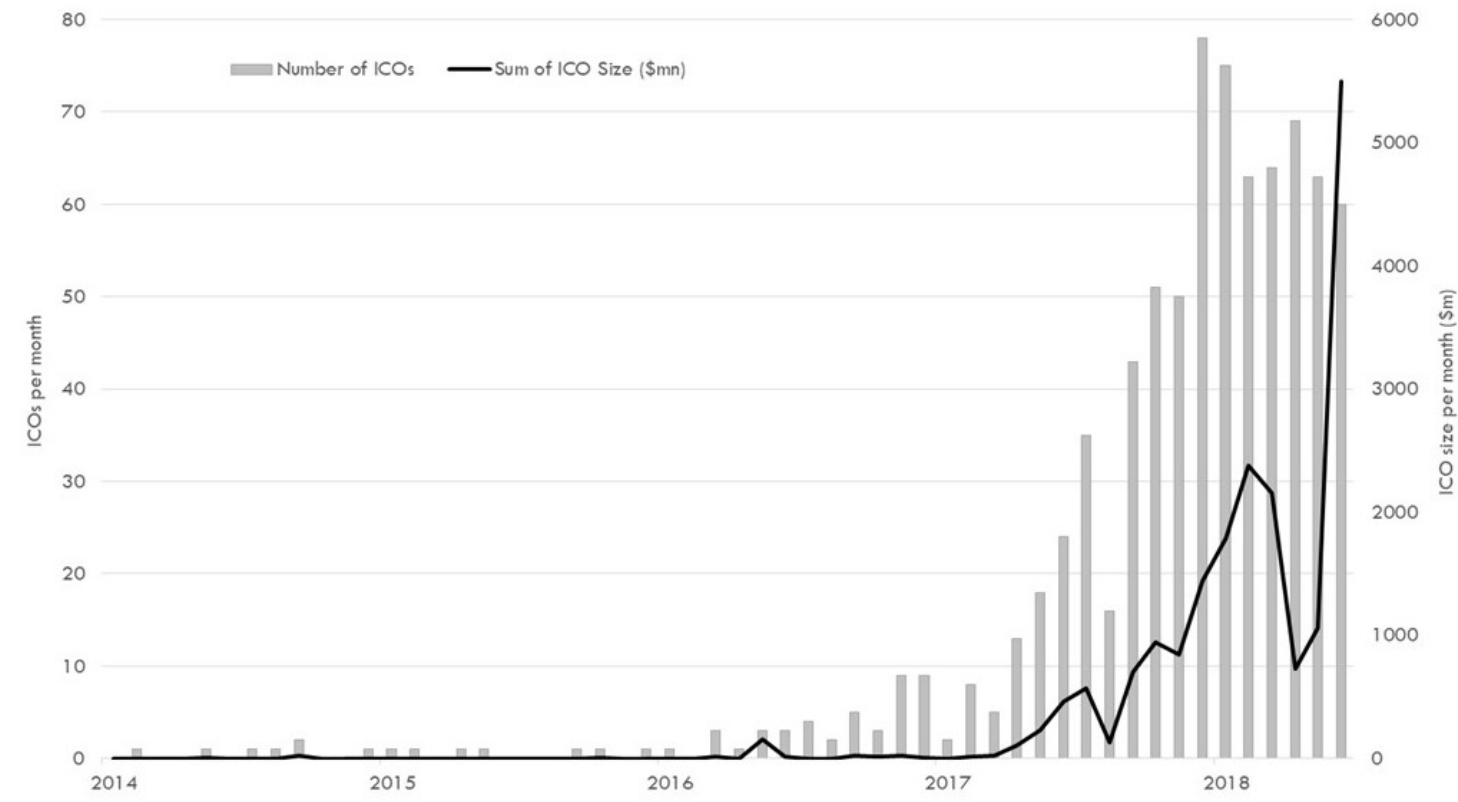

Note: Data was available between 1 January 2014 and 31 July 2018. Data was obtained from www.coindesk.com. The above bars represents the number of ICOs initiated per month while the black line represents their size as measured in US\$ millions.

of the ICO simply disappears. Unfortunately, this type of scam has become far too common in recent times. Amongst the most well-known is that of Pincoin, representing one of the largest ICO scam in history. Together with Ifan, another blockchain company, 32,000 investors were duped out of the equivalent of $\$ 660$ million. The company had promised its investors a $40 \%$ monthly returns on their investment, luring unsuspecting investors with claims that the ICO was to be overseen by PIN Foundation. Further, Modern Tech promised an $8 \%$ reward to every investor for bringing in another investor, indicative of a classic multi-level-marketing scheme with the benefit of hindsight. Titanium was another example of a textbook ICO case of fraud. The ICO was based on a social media marketing blitz that allegedly deceived investors with purely fictional claims of business prospects. Charges were then filed against Michael Alan Stollery, a self-described blockchain evangelist, who is reported to have lied about business relationships with the Federal Reserve and dozens of well-known firms, including PayPal, Verizon, Boeing, and The Walt Disney Company. The complaint alleges that Titanium's website contained fabricated testimonials from corporate customers. As evidence of the sharp perceptions and actions of regulatory authorities, the Titanium ICO was stopped before it was finished. 
In 2016, over $\$ 30$ million dollars were seized by Chinese authorities investigating the OneCoin operation in the country. The company claimed to be officially licensed in Vietnam, but this was later refuted by the country's government. More than five countries have warned investors of the risks involved for those choosing to invest in the company, including Thailand, Croatia, Bulgaria, Finland and Norway. In 2017, another example of substantial ICO fraud was that of Confido, who had collected 1235 Ethereum, at the time valued at approximately $\$ 375,000$ before the price of tokens became tradable and their value subsequently skyrocketed. At one point, the price of one CFD token rose approximately that of twenty times the amount of the initial ICO price. This price jump made Confido one of the best-performing ICOs ever in terms of short-term token price rise, and the tiny project possessed a market cap of $\$ 10$ million in a very short amount of time. However, a number of market monitors had raised suspicions based on the lack of credibility and the continued anonymity of those responsible. Thereafter, a message on Confido's subreddit said that the company is having unspecified legal problems which will delay development 'until a resolution is found.' Shortly after, the value of CFD had collapsed to $\$ 0.03$ and all associated had become non-responsive.

BitConnect closed down its crypto-lending platform in January 2018 following the issuance of cease-and-desist orders from Texas and North Carolina securities regulators, which claimed the company was engaging in an unregistered securities sale through its initial coin offering (ICO). Users exchanged Bitcoin for Bitconnect Coin (BCC) on the Bitconnect platform which had launched in January 2017, and were promised substantial returns on their investments. There were broad accusations and signs that there existed a broad ponzi scheme referral system. BitConnect's BCC token plunged more than 90 percent, falling from over $\$ 400$ to less than $\$ 20$ in the first weeks of 2018. A number of users have since launched a class action lawsuit against Bitconnect to recoup lost funds.

Further, in a quite astonishing case in 2018, in a creditor protection filing from the Nova Scotia Supreme court, QuadrigaCX passed on 9 December 2018, leading to a liquidity crisis at the exchange. CEO Gerald Cotten had died of complications with Crohn's disease 'while travelling in India, where he was opening an orphanage to provide a home and safe refuge for children in need.' The company had said that Cotten was the sole person with passwords to access the exchange's 'cold storage,' where the vast majority of its client holdings were held. QuadrigaCX filed for creditor protection in compliance with the Companies' Creditors Arrangement Act (CCAA). The exchange only has CA $\$ 375,000$ in cash, while it owed approximately CA $\$ 260$ million to its users. The exchange kept most its assets in offline storage systems called cold wallets, which are secured by digital security keys in order to protect them from hacking and theft. Cotten was solely responsible for the wallets and corresponding keys, which the company has been trying to find after 
his passing ${ }^{1}$. The company's auditors raised substantial, ongoing suspicions when they wrote in a 2019 report that they had 'been unable to locate any traditional books and records, including accounting records documenting Quadriga's financial results and operations following 2016'.

In April 2019, The founder of German-based startup Savedroid has allegedly disappeared after raising a reported $\$ 50$ million through both an ICO and private funding. It was later reported that Savedroid's CEO posted a video to YouTube claiming that the apparent exit scam was actually a PR stunt the company pulled off to advocate for 'high quality ICO standards.' This type of behaviour again presents further evidence of the non-standard incidents that have been repeatedly occurring in the market for ICOs, generating substantial erosion of trust while verifying continued suspicion on behalf of regulators and market participants alike.

\subsection{Facebook and Project Libra}

One of the largest ICO-related announcements in recent times surrounded that of Project Libra, which is a proposed digital currency by that of Facebook with an estimated launch date during 2020. The project, currency and transactions are to be managed and cryptographically entrusted to the Libra Association, which was founded by Facebook's subsidiary Calibra and a number of other companies across payment, technology, telecommunication, online marketplace, venture capital and nonprofits. It was first rumoured in May 2019 that Facebook had been secretly planning to release a cryptocurrency, with names reported such as GlobalCoin and Facebook Coin. The new coin is not proposed to be decentralised, thereby firmly relying on trust in the Libra Association as a lender of last resort. The company also announced a new digital wallet called Calibra, which will be operated by Facebook as a separate subsidiary and provide users with a way to store and spend Libra. Facebook provided an image of Calibra's design, including a three-wave symbol that serves as the Libra's equivalent of a dollar sign. The currency's blockchain, which is open source, will be programmed in a new language developed by Facebook called Move. Facebook will invite third parties to build smart contracts and other blockchain-based services. The proposed idea to leverage upon the already global Facebook network, utilising a token which would be backed by financial assets including currencies and US Treasury securities in an attempt to mitigate issues with volatility, with substantial financial support to be provided by a variety of companies that have already offered their support to the idea. The Libra Association will thereby create new Libra currency units based on demand while previous currency units will be retired as they are redeemed for conventional currency. In the related white paper, it was proposed that the reconciliation of transactions will be performed at each service partner, and the blockchain's distributed ledger will be used for reconciliation between service partners which would theoretically prevent an association

\footnotetext{
${ }^{1}$ However, it was widely reported that Cotten mostly worked from his computer at home, which is encrypted. Cotten's wife, Jennifer Robertson, reportedly stated in an affidavit, 'I do not know the password or recovery key. Despite repeated and diligent searches, I have not been able to find them written down anywhere.'
} 
member extracting and analysing the distributed ledger. In a May 2002 report in the Wall Street Journal, it was widely reported that there were a number of additional business models and benefits that Facebook was considering to be central to the creation of Libra, including: 1) a plan to launch a full payments network while the company had been reportedly in discussions with payment networks Visa and Mastercard, payments processors such as giant First Data as well as large e-commerce merchants to support the launch; 2) that Facebook had been the ability to generate up to $\$ 1$ billion in investments collectively from associated firms to provide collateral to bolster and back the stablecoin that will be associated with the new payments network; 3) the new coin will exist as the currency of the payments system in order to eliminate credit card fees for merchants as well as to avoid the volatility of other cryptocurrencies like Bitcoin and Ether; and 4) the new coin could potentially be tied to Facebook's core advertisement engine, thereby rewarding users for viewing advertisements and then purchasing goods, similar to how loyalty points rewards work.

The announcement of Libra's coincided with unprecedented scrutiny from regulators surrounding Facebook's actions and behaviours across multiple fronts in recent years. The company has spent much time since 2017 battling to regain user trust after multiple privacy scandals, thereby experiencing much scepticism when Project Libra was initially announced. Since Libra's unveiling, the project has received quite a negative reception from some policymakers. The United States Federal Reserve Chairman Jerome Powell signalled much scepticism about Facebook's plans for Libra, stating that he did not 'think that the project can go forward' and that it was of the utmost importance that there be 'broad satisfaction with the way the company has addressed money laundering' during testimony before the House Financial Services Committee. Regulators had possessed 'serious concerns' with the project in its entirety when gauging its potential from the previous announcements. It has also not been identified as to whether money has actually changed hands from members who had expressed interest in the Libra association as some of the companies who agreed to lend their names to the project avoided making strong public statements in support of it. This very fact reflected significant uncertainty about how Libra will actually work and even if it is possible to launch a network like this within the bounds of international law, potentially explaining the reluctance for some companies to offer support. At the core of this project, Facebook is trying to build a payment system that combines the best characteristics of blockchain and conventional networks. But the result may wind up just being a contradictory and jurisdictional, regulatory and legislative disaster. Amongst one of the key issues is whether Libra will actually provide meaningful privacy to its users, particularly as Facebook's plan incorporates delegating responsibility of the company's network to its subsidiary Calibra, where Facebook executives have stated that Calibra will not share account holder's purchase information with Facebook without authorisation. After the multiple privacy issues that have occurred in recent times, this is highly unlikely to lead to a positive response from users.

The European response has been far more damning. In September 2019, French finance min- 
ister Bruno Le Maire stated that the nation will not allow the development of the cryptocurrency in Europe as it is a threat to the monetary sovereignty of nations. He also spoke about the potential for abuse of marketing dominance and systemic financial risks as reasons for not allowing cryptocurrency in Europe. He announced that the French government refused to authorise the development 'on the European soil'. He continued to state that 'the monetary sovereignty of states is at stake. Any failure in the functioning of this currency, in the management of its reserves could create considerable financial disorders'. One of the major fears around the Libra is that it replaces the national currency in states where the currency is weak or experiencing a strong devaluation. There are also substantial fears that cryptocurrency escapes control over the financing of terrorism. In early August 2019, a joint statement by several regulators in charge of personal data protection, in the US, Europe, the UK, Canada and Australia, summoned the social network to give guarantees in this area. The EU's competition authority subsequently begun investigating Libra, fearing 'possible impediments to competition'. From a political standpoint, the United States House Committee on Financial Services Committee asked Facebook to halt the development and launch of Libra, citing a list of recent scandals and that 'the cryptocurrency market currently lacks a clear regulatory framework'. Further, the US House Committee on Financial Services Democrats later sent a letter to Facebook asking the company to stop development of Libra, citing concerns of privacy, national security, trading, and monetary policy. In one of the most damning attacks on the planned cryptocurrency, Jerome Powell, chair of the Federal Reserve, testified before Congress on 10 July 2019 that the Federal Reserve had 'serious concerns' as to how Libra would deal with 'money laundering, consumer protection and financial stability'. It would be very much considered that the project, even after substantial development will face considerable opposition at all stages prior to establishment and throughout the process international regulatory alignment.

\subsection{Venezuela and the Petro}

In mid-December 2018, the Venezuelan economy is estimated by the IMF to have exceeded $1,000,000 \%$ price inflation, otherwise identified as hyperinflation, combined with a premium of approximately $2,500 \%$ between its official currency, the bolivar, and a black-market exchange rate that has been thriving under the influence of those with access to the official rate at source. Throughout 2018, the Venezuelan government under the leadership of President Nicolas Maduro have established a number of routes through which they could reduce the burden of economic collapse. Primarily, a new sovereign bolivar (bolivar soberano) was identified to replace the old bolivar (bolivar fuerte) at a conversion rate of 100,000:1, indicating that 100,000 old bolivars was the equivalent of US $\$ 1.5$ cent $^{2}$. Other countries with high levels of inflation, like Zimbabwe and Ecuador, have escaped by

\footnotetext{
${ }^{2}$ We must note that the greatest level of hyperinflation was identified in Hungary, where the daily inflation rate reached $207 \%$ in July of 1946 , leading to a currency reform on August 1, 1946. The Pengo was replaced by the Forint, and the conversion rate was 400 octillion Pengo to one Forint.
} 
adopting the dollar, which would most likely be politically unacceptable for Mr Maduro's regime. Zimbabwe pegged their economy to the US dollar when citizens refused to accept payments in the local currency. In Venezuela, which deprives people of access to dollars more effectively than did Zimbabwe (noting that the Zimbabwean economy underwent four rounds of redenomination and the printing of the $\$ 100$ trillion bill before resorting to building a new currency), people could switch from the bolivar to the Petro.

This innovative product aimed at restructuring the Venezuelan economy was launched in February 2018 through the Petro, indicative of a cryptocurrency that would be supported 'by oil assets and issued by the Venezuelan State as a spearhead for the development of an independent, transparent and open digital economy open to direct participation of citizens'. The associated product white-paper' ${ }^{3}$ states that 'Venezuelan oil assets will be used to promote the adoption of crypto assets and technologies based on the country's block-chain...... The Venezuelan population will have at their reach a technology that will allow them having a valuable reserve and robust means of payment to stimulate savings and contribute to the country's development. Petro will be an instrument for Venezuela's economic stability and financial independence, coupled with an ambitious and global vision for the creation of a freer, more balanced and fairer international financial system'. The base price of the Petro was denoted at one barrel of oil. The link to oil is no more convincing. The Petro is not yet itself exchangeable for oil. It is simply backed by a government's guarantee that it is backed by oil. The very creation, advertisement and distribution of such a currency during a period of exceptional economic strife generated substantial concern about the credibility of this ground-breaking sovereign asset. The Petro's pre-sale to investors began on 20 February 2018, where 38.4 million tokens were made available until 19 March 2018. The Venezuelan government stated that US $\$ 3.3$ billion was raised through the sale but this has yet to be independently verified. We must also note that one of the very characteristics of a cryptocurrency is that it be free of government intervention, explicitly decentralised from central bank authority.

The introduction of the Petro is quite similar to the German government's decision to introduce the Rentenmark to stem the growth of hyperinflation during the 1920s. The Rentemark was made stable through the backing of property used for agriculture and business, tangible products through which the German population could hold as security to underpin the value of the Papiermark. This is one of the key differences when observing the Petro and it's underlying fulcrum. Without explicit backing, this product is simply driven by unsupported market sentiment, offering little for a population desperate for economic stability. Although not the first Venezuelan cryptocurrency, products such as Bolivarcoin, Onixcoin, Rilcoin and Perlacoin have preceeded Petro, however, each have had little purchase internationally. When initially announced in December 2017 by President Maduro, one major concern was identified in this new cryptocurrency's ability to circumvent US sanctions

\footnotetext{
${ }^{3}$ Available at: https://www.petro.gob.ve/
} 
that had been implemented on the Venezuelan economy and their ability to access international financing. Officials of Iran and Russia have said their governments might be interested in issuing cryptocurrencies. The Marshall Islands announced that it would issue one, called the sovereign, that it will accept as legal tender. The Marshall Islands is a dollarised economy; a second currency would give it at least the illusion of greater control over its money. Iran and Russia are subject to American sanctions. The one common theme throughout these envisaged planned cryptocurrencies is a non-standard relationship between these countries and the economy of the United States. The US Department of the Treasury have explicitly warned that investor's partaking in the initial coin offering of Petro would be in breach of such sanctions that have been imposed on countries such as Venezuela.

The ethical underpinning that supports the generation of the Petro is somewhat opaque. A number of rating agencies, international economists and news agencies have all stated that this product is nothing more than a scam and a product to circumvent restrictions while providing false hope to a desperate population. The project has been identified as missing critical information, from the description of the mechanism to its technology and supposed oil-backing. The underlying technology supporting the product has been broadly challenged and has throughout 2018 changed substantially from that information provided in the Petro's original white-paper. The principal platform for the coin is NEM, where accounts are anonymous, but can disclose their identities in the description of their coins if they wish. The Venezuelan government issued 82.4 million tokens from an NEM account in March 2018 described as preliminary coins. The product has continued to evolve as a product who's underlying structure remains fluid, but this is not a unique selling point, in fact, it would raise fears that there is a strong theme of desperation from economic collapse at the foundations of the necessity for this outlier sovereign product designed specifically to 'petrolise' salaries and prices. The Petro has also continued to obtain support from a number of international exchanges. Hong Kong-based Bitfinex, one of the world's largest exchanges by volume, in March said it never intended to list the Petro due to its 'limited utility.' The only exchange that has publicly discussed plans to list the Petro is India's Coinsecure. As of late 2018, the product remains untraded. The technology behind the coin is said to be in development while nobody has been able to make use of the Petro despite claims of substantial investment at the time of the ICO. Further, a number of international journalist who have contacted the Venezuelan government for comment remain unanswered while the Superintendence's website is unresponsive. In August 2018, President Maduro announced that salaries, pensions and the exchange rate for the bolivar would be pegged to the Petro, thereby underpinning the economy to the simplistic assumption that one barrel of oil (priced at approximately $\$ 66$ at the time that this peg had taken place, backed with crude oil reserves located in a 380-square-kilometre area surrounding Atapirire ${ }^{4}$ ) is equivalent to one Petro.

\footnotetext{
${ }^{4}$ To date, there is no evidence of oil accumulation at this site
} 
This statement and the precarious nature of this sovereign cryptocurrency presented a strong signal of the desperation that had now taken over, that a government would simply rest their economic future (although already bleak) on an exceptionally high-risk, high-volatility, untested, unverified and most likely illegal product.

\subsection{KodakCoin and other examples of corporate manoeuvres}

On the 9 of January 2018, camera manufacturer Kodak announced that it was entering the cryptocurrency market through the creation of KODAKOne, described as a revolutionary new image rights management and protection platform secured in the blockchain. Kodak announced that its development seamlessly registers, manages and monetises creative assets for the photographic community (Corbet et al. [2019]). It would be used to underpin the assured buying and selling of rights-cleared and protected digital assets while ensuring transparency. The announcement had a significant sharp impact on volatility (which peaked at over $60 \%$ per day) with shares increasing from over $\$ 3$ per share to over $\$ 12$ in less than one week. This was associated with an increase in market sentiment and research using terms such as 'Kodak' and 'KODAKCoin'. Kodak CEO Jeff Clarke said in a press statement, 'For many in the technology industry, 'blockchain' and 'cryptocurrency' are hot buzzwords, but for photographers who've long struggled to assert control over their work and how it's used, these buzzwords are the keys to solving what felt like an unsolvable problem.' In theory, photographers will be able to upload their images to a platform called KodakOne, create a blockchain-based license for each image, and use web-crawling software to scour the internet looking for copyright violations. Instead of using dollars, photographers can have clients pay them in KODAKCoins. However, there are many analysts and market-commentators alike that continue to identify Kodak's strategy as a technique to capitalise on the current cryptocurrency frenzy or is it indeed a valid evolutionary characteristic of blockchain.

The results provided by Corbet et al. [2019] indicate a substantial and sustained increase in return volatility in the period after the announcement of Kodak's intention to create a cryptocurrency. Such announcements can potentially take advantage of the euphoric and speculative investment motives that have been inflating what some consider to be a significant bubble in cryptocurrency markets. Announcements without strong supporting evidence can present an channel through which speculative contagion can flow from cryptocurrency markets to equity markets. The definition provided by the US Securities and Exchange Commission for a 'pump-and-dump' specifically comes to mind, that often occur on the internet where it is common to see messages posted that urge readers to buy a stock quickly or to sell before the price goes down, or a telemarketer will call using the same sort of pitch. Often the promoters will claim to have 'inside' information about an impending development or to use an 'infallible' combination of economic and stock market data to pick stocks. In reality, they may be company insiders or paid promoters who stand to gain by selling their shares after the stock price is 'pumped' up by the buying frenzy they create. Once these fraudsters 'dump' 
their shares and stop hyping the stock, the price typically falls, and investors lose their money. These 'sudden' cryptocurrency announcements have also attracted the attention of regulators. Jay Clayton, the chairman of the Securities and Exchange Commission (SEC), said that the agency was 'looking closely at the disclosures of public companies that shift their business models to capitalise on the perceived promise of distributed ledger technology.' However, Kodak then decided to delay the ICO of KODAKCoin in an attempt to verify accredited status of approximately 40,000 potential investors. The SEC requires that an individual accredited investor has a net worth that exceeds $\$ 1$ million, or an annual income of at least $\$ 200,000$, along with other conditions. The company claims it needs 'several weeks' to verify the 'accredited investors' status of those who applied to invest in the ICO. Potential investors from outside the US would then be considered in accordance with their local jurisdictions. But one key point that can be taken from the case of Kodak is that it's price, two months later, remained elevated by almost 100\% of that from early January 2018. Even without the implementation of an ICO, the announcement of a cryptocurrency related plan has potentially incorporated any cryptocurrency speculation into the share price of a publicly traded company. This is a point of concern for regulators and policy-makers alike.

While Kodak provide an example of a company that has attempted to incorporate cryptocurrency into their non-cryptocurrency-related business practices, there have also been a number of companies that have gone one-step further and attempted to change their names to identify as a cryptocurrency-related company. This is even more astonishing as some of these companies for the most-part had no prior interaction with any form of IT or technological development. In a detailed analysis investigating both the financial market effects and the theoretical grounding or indeed ethical support surrounding such decisions, Akyildirim et al. [2019] found that thirty-one companies are identified to have partaken in 'crypto-exuberant' naming behaviour. In 2015 and 2016, there are only two companies, NXChain and First Bitcoin Capital that change their names, previous known as AgriVest Americas and Grand Paracaraima Gold respectively. In 2017, there are twelve companies who then change their names, and eleven in 2018. When comparing the companies who had partaken in crypto-exuberant company announcements, those who have utilised cryptocurrency and blockchain when naming are found to have on average higher returns, yet more volatile returns with mean returns of $-0.0081 \%$ and a standard deviation of $5.1575 \%$. Further, such companies exhibit far more substantial extreme returns (where evidence is provided of one-day price decreases of $52.8 \%$ and increases of $57.7 \%$ when compared to $-15.9 \%$ and $16.9 \%$ in non-cryptocurrency companies respectively), further associated with skewness and kurtosis in excess of three times that of other non-cryptocurrency-based company names. Such a result indicates that companies that partake in the use of cryptocurrency-based naming practices are found to be substantially riskier shares to purchase when compared to other companies that have changed their corporate name for other types of reasons.

Quite incredibly, there have also been two companies who have actually changed their name 
twice, in both cases from a non-crypto-exuberant name to a crypto-exuberant name and then back again. In August 2018, Focused Capital II Corp announced its intention on the TSX Venture Exchange to change its name to Fortress Blockchain Corp, clearly positioning its corporate identity to be further associated with the growing blockchain and cryptocurrency markets. During this transaction, the company issued 71.2 million common shares and signalled its intention to begin trading on the TSXV under the ticker 'FORT'. In a largely unanticipated move, in April 2019, Fortress Blockchain then applied to the TSX Venture Exchange to change its name to Fortress Technologies Inc while continuing to use the same ticker. This situation is the only identified case within the dataset of a company retracting on its decision to partake in crypto-exuberant behaviour. However, Long Island Iced Tea Corp. remains as one of the most famous companies to employ a crypto-exuberant naming strategy when changing their corporate identity to Long Blockchain Corp in 2017. The stock price then sharply increased almost 300\% stating that it was 'shifting its primary corporate focus' from tea to distributed-ledger technology. In 2019, it has been announced through warrants in the United States that the FBI is looking for evidence of insider trading and securities fraud connected to Long Island Iced Tea stock, where two men related to a separate company, were arrested for securities fraud. There have also been broad accusations about the presence of a 'pump-and-dump' scheme, where promoters buy a cheap stock, start hyping it to investors with eye-catching claims, then sell their own holdings during the resulting mania, hopefully securing a profit before the stock comes crashing down. Based on a number of text messages that the FBI have since uncovered, they are interested in a person known as 'Eric W' in a series of messages, where the accused person owned approximately $15 \%$ of the shares in Long Island Iced Tea at the time that the company's name was changed. There is further investigation into the use of an investor relations program to develop hype around the company during this time. Riot Blockchain has also been investigated throughout 2018 and 2019 by the SEC. It had previously changed its name from Bioptix, where its previous business practices was based on the development of veterinary products patent and developing new ways to test for disease.

\section{How has the regulation of ICOs changed over time?}

While clearly portraying evidence of the multiple issues that the market for ICOs have experienced in recent times, including that of moral hazard, adverse selection, insider trading and market manipulation amongst others, and the very fact that participants have been continuously proven to have acted out outside existing regulatory frameworks, have caused much distrust within the broad ICO market. In many cases there was an absence of due diligence, standardised financial reporting, prospectuses containing the main risk factors of the company and its businesses and broad corporate governance. Instead, many fund providers to these projects released whitepapers with poor information, in some cases omitting the name of the company or its address, however, focusing on 
marketing techniques, even in some cases using celebrities in an almost tactical capacity to distract investors. The first responses from national regulators around the world focused on warnings and guidance while providing thorough investigations with reports and outright bans (such as that seen in China in September 2017). Most regulators would agree that although ICOs are currently not governed by specific regulations, the broad practices of many ICOs might already fall under existing legal and jurisdictional coverage. Recently, it has been discussed that some ICOs might actually be contained within the scope of regulation focused on Initial Public Offerings (IPOs), private placement of securities, crowdfunding or even collective investment schemes.

The development and growing sophistication of international regulatory scrutiny has somewhat alarmed cryptocurrency entrepreneurs. In the past, the rapidly expanding ICO landscape resembled a free for all, where the most talented and knowledgeable appear to have been taking funds from the most vulnerable who were seeking quick profit. The negative media coverage on cryptocurrency criminality has most certainly attracted the attention of regulatory authorities. The effect of increased scrutiny by authorities has been to multiply regulatory barriers for entrepreneurs aspiring to begin an ICO. However, this has generated some confusion. There has been considerable controversy over the status of utility tokens, which require fewer disclosure forms and checks from the SEC and which are favoured by most startups opting for an ICO. The SEC were seen to have adequately forewarned cryptocurrency startups when asserted that most ICO tokens would require greater disclosure, the first time that the commission had clarified its stance regarding ICOs. The increased level of regulation for a security token sale appears to have made ICOs costlier while taking more time as compared to an ICO for utility tokens, where the average cost is estimated to be between $\$ 1$ million and $\$ 3$ million for a security token sale. Private sales to accredited investors also shift costs of conducting a public ICO. Entrepreneurs have increasingly begun issuing a bonus (or discount) on their tokens to private investors.

When the SEC released the 'Framework for Investment Contract Analysis of Digital Assets' in April 2019, many in the cryptocurrency community were unhappy with the broad definition which the SEC applied to securities, which left little room for true utility tokens. Initial Exchange Offerings (IEOs) have been another area in which regulators and cryptocurrency innovators have recently developed contrasting opinions. The largest concerns for the users of cryptocurrencies has been the security as a multitude of hacking events have generated many negative reverberations throughout the industry. It is against this backdrop that more regulatory oversight has become necessary.

Regulators must also continue to monitor the growth of online casinos, who have somewhat recently revolutionised the world of gambling through the use of cryptocurrency in online casinos. It is now possible to gamble using Bitcoin amongst other cryptocurrencies, which had been found to improve the security of your gambling experience. More online casinos have started accepting cryptocurrency in a bid to attract younger players, which further provides an anonymous playing 
experience and improve the transaction processes. This also generates widespread issues with regards to the taxation and cross-border monitoring of fund flows and has been identified one of the trends that has contributed to the immense growth of the online gambling industry.

\section{Concluding Comments}

In this chapter, we provide a thorough account of the key issues that have engulfed the ICO market in recent years, somewhat stifling the growth of illicit cryptocurrency auctions, but further failing to eliminate the issue completely. A central theme throughout these listed issues and examples surrounds substantial damage to credibility within the market. We have observed cases of theft at the level of the exchange, within the whitepapers that have been provided, through the usage of celebrities to support marketing tactics, through the illegal cross-jurisdictional transfer of funds and indeed, the most simplest form of theft, where the ICO counter-party quite simply disappears with the accumulated assets of investors. While cryptocurrency-enthusiasts continue to promote the positive attributes that support the potential growth of this new investment asset, the same proponents cannot ignore that this entire sector has been rampant with levels and styles of fraudulent behaviour that is quite difficult to find in other international markets of similar scale and scope. But there have been significant positive developments in terms of the future scope of international regulation and the potential to eliminate fraudulent behaviour. It is essential that during the continued growth of the sector for cryptocurrencies that regulation, including a broad international set of standards, be developed and maintained to grow at pace with the market for cryptocurrencies. It is essential that regulations must compare effectively with the sophistication of the market that they attempt to monitor. Until the broad gap between regulation and the capacity for cryptocurrency market misuse is diminished, there will continue to be substantial and frequent loss of investor assets through mechanisms that represent those usually observed in an exceptionally juvenile market.

\section{Bibliography}

Adhami, S., G. Giudici, and S. Martinazzi (2018). Why do businesses go crypto? an empirical analysis of initial coin offerings. Journal of Economics and Business 100, 64-75.

Akhtaruzzaman, M., A. Sensoy, and S. Corbet (2019). The influence of bitcoin on portfolio diversification and design. Finance Research Letters.

Akyildirim, E., S. Corbet, A. Sensoy, and L. Yarovaya (2019). How has the intention to incorporate blockchain technology affected information asymmetry and the transparency of corporations? Available at SSRN. 
Barone, R. and D. Masciandaro (2019). Cryptocurrency or usury? crime and alternative money laundering techniques. European Journal of Law and Economics 47(2), 233-254.

Celeste, V., S. Corbet, and C. Gurdgiev (2019). Fractal dynamics and wavelet analysis: Deep volatility and return properties of bitcoin, ethereum and ripple. Quarterly Review of Economics and Finance.

Chen, K. (2019). Information asymmetry in initial coin offerings (icos): Investigating the effects of multiple channel signals. Electronic Commerce Research and Applications 36.

Cohney, S., D. Hoffman, J. Sklaroff, and D. Wishnick (2019). Coin-operated capitalism. Columbia Law Review 119(3), 591-676.

Cooper, M., O. Dimitrov, and P. Rau (2001). A Rose.com by any other name. Journal of Finance 56, $2371-2387$.

Corbet, S., V. Eraslan, B. Lucey, and A. Sensoy (2019). The effectiveness of technical trading rules in cryptocurrency markets. Finance Research Letters 31, 32-37.

Corbet, S. and P. Katsiampa (2018). Asymmetric mean reversion of bitcoin price returns. International Review of Financial Analysis In Press, Available Online at: https://doi.org/10.1016/j.irfa.2018.10.004.

Corbet, S., C. Larkin, B. Lucey, A. Meegan, and L. Yarovaya (2020). Cryptocurrency reaction to fomc announcements: Evidence of heterogeneity based on blockchain stack position. Journal of Financial Stability 46 .

Corbet, S., C. Larkin, B. Lucey, and L. Yarovaya (2019). Kodakcoin: a blockchain revolution or exploiting a potential cryptocurrency bubble? Applied Economics Letters, 1-7.

Corbet, S., B. Lucey, M. Peat, and S. Vigne (2018). Bitcoin futures - what use are they? Economics Letters 172, 23-27.

Corbet, S., B. Lucey, A. Urquhart, and L. Yarovaya (2019). Cryptocurrencies as a financial asset: A systematic analysis. International Review of Financial Analysis 62, 182-199.

Corbet, S., B. Lucey, and L. Yarovaya (2018). Datestamping the Bitcoin and Ethereum bubbles. Finance Research Letters 26, 81-88.

Corbet, S., A. Meegan, C. Larkin, B. Lucey, and L. Yarovaya (2018). Exploring the dynamic relationships between cryptocurrencies and other financial assets. Economics Letters 165, 28-34.

Deng, H., R. Huang, and Q. Wu (2018). The regulation of initial coin offerings in china: Problems, prognoses and prospects. European Business Organization Law Review 19(3), 465-502. 
Felix, T. and H. von Eije (2019). Underpricing in the cryptocurrency world: evidence from initial coin offerings. Managerial Finance 45(4), 563-578.

Fisch, C. (2019). Initial coin offerings (icos) to finance new ventures. Journal of Business Venturing $34(1), 1-22$.

Foley, S., J. R. Karlsen, and T. J. Putnins (2019). Sex, drugs, and Bitcoin: How much illegal activity is financed through cryptocurrencies? Review of Financial Studies 32, 1789-1853.

Gandal, N., J. Hamrick, T. Moore, and T. Oberman (2018). Price manipulation in the Bitcoin ecosystem. Journal of Monetary Economics 95, 86-96.

Griffins, J. and A. Shams (2018). Is Bitcoin really un-Tethered. SSRN Working Paper.

Hashemi Joo, M., Y. Nishikawa, and K. Dandapani (2019). Icos, the next generation of ipos. Managerial Finance.

Huang, W., M. Meoli, and S. Vismara (2019). The geography of initial coin offerings. Small Business Economics.

Katsiampa, P., S. Corbet, and B. Lucey (2019). Volatility spillover effects in leading cryptocurrencies: A bekk-mgarch analysis. Finance Research Letters 29, 68-74.

Lahajnar, S. and A. Rozanec (2018). Initial coin offering (ico) evaluation model. Investment Management and Financial Innovations 15(4), 169-182.

Nakamoto, S. (2008). Bitcoin: A peer-to-peer electronic cash system.

Nguyen, T., B. Nguyen, T. Nguyen, and Q. Nguyen (2019). Bitcoin return: Impacts from the introduction of new altcoins. Research in International Business and Finance 48, 420-425.

O'Dair, M. and R. Owen (2019). Financing new creative enterprise through blockchain technology: Opportunities and policy implications. Strategic Change 28(1), 9-17. 